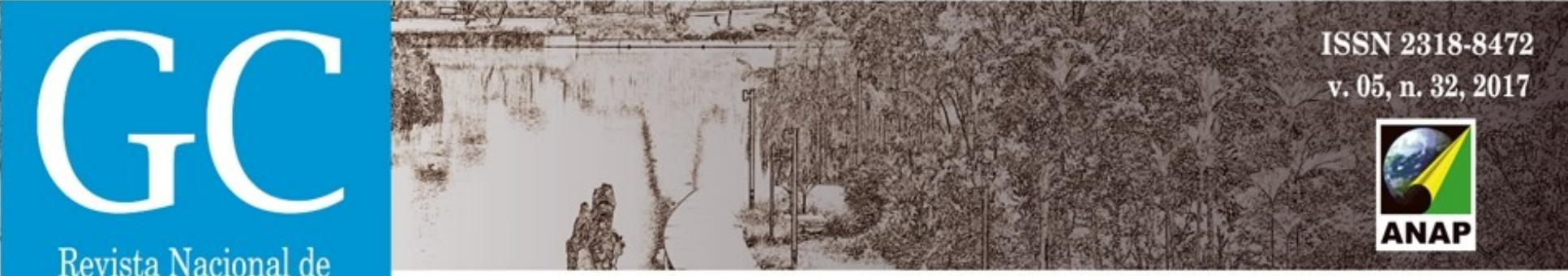

\title{
Complexo Portuário da Grande Vitória (ES) e Plano de Desenvolvimento e Zoneamento Portuário: um debate recente
}

\author{
Grande Vitória Port Complex (ES) and the Port Development and Zoning Plan: a recent \\ debate
}

Complejo Portuario de la Gran Victoria (ES) y Plan de Desarrollo y Zonificación Portuaria: un debate reciente

\author{
Henrique Alexandre Silvestre \\ Aluno de Mestrado, UFES, Brasil \\ silvestrehenrique@hotmail.com \\ Martha Machado Campos \\ Professora UFES, PosDoc, UFRJ, Brasil \\ marthamcampos@hotmail.com
}




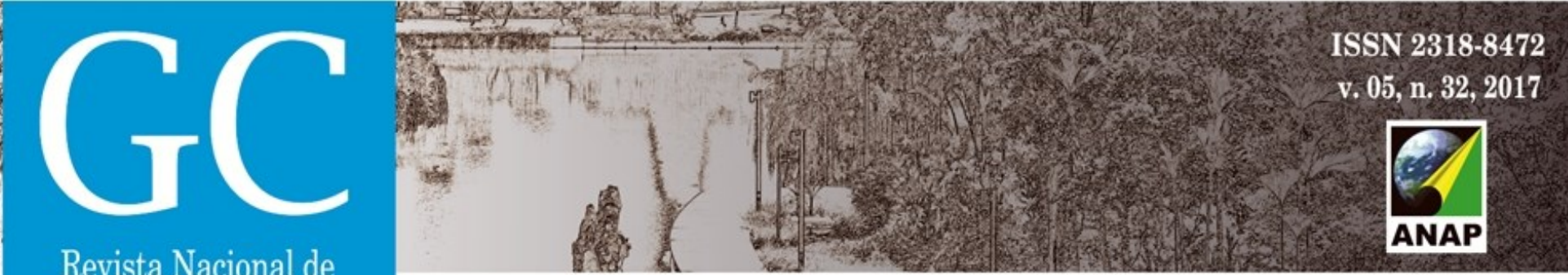

Gerenciamento de Cidades

National Journal of Cities Management

Figura 1: Área planejada de aterro na baía de Vitória, segundo PDZP de 2001 e 1995
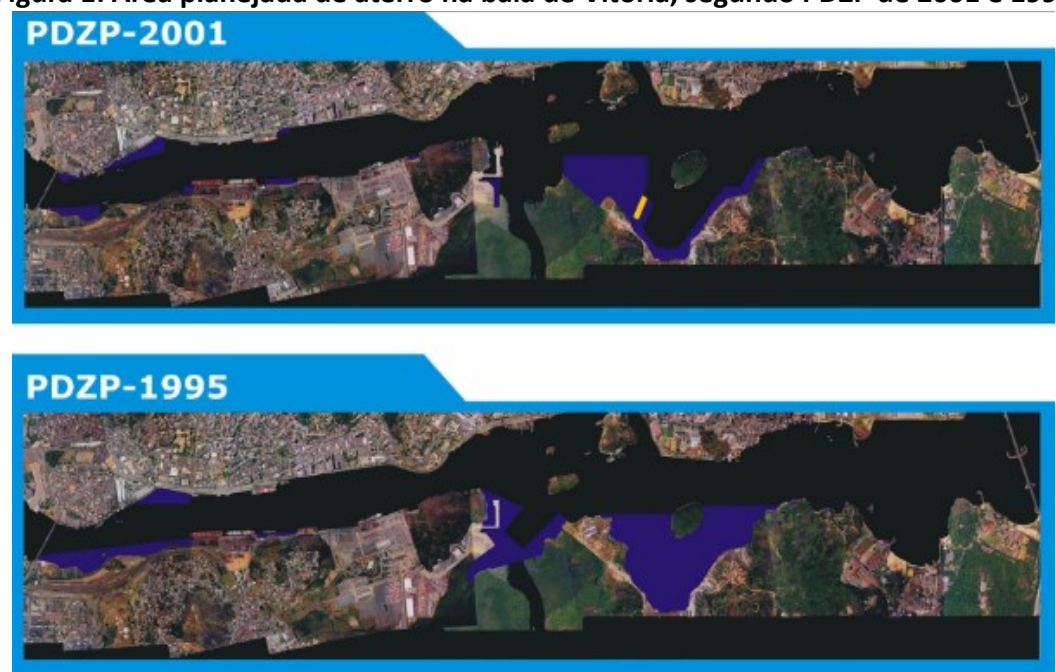

Fonte: CODESA, 2001.

Figura 2: Área planejada de aterro no município de Vila Velha, segundo PDZP de 1995

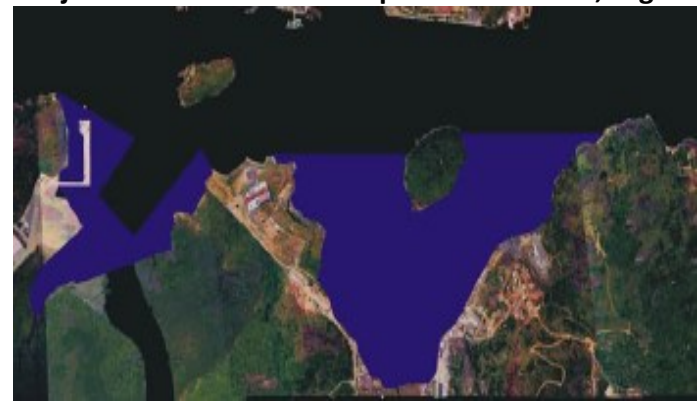

Fonte: CODESA, 2001.

Na figura 3, já constante no PDZP de 2001, é detectável a mudança de abordagem para o sítio em questão, com considerável diminuição das áreas a serem aterradas. Ainda hoje esta zona da face litorânea do município de Vila Velha permanece sem a inserção desses elementos. 


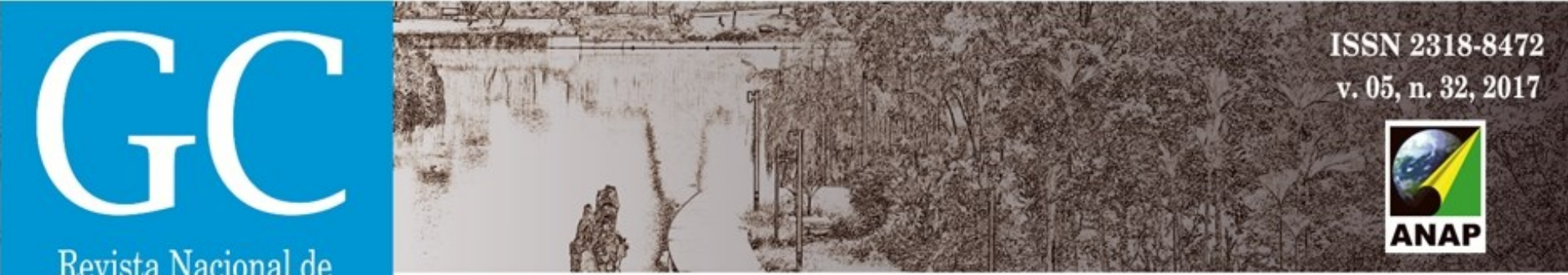

Figura 3: Área planejada de aterro no município de Vila Velha, segundo PDZP de 2001

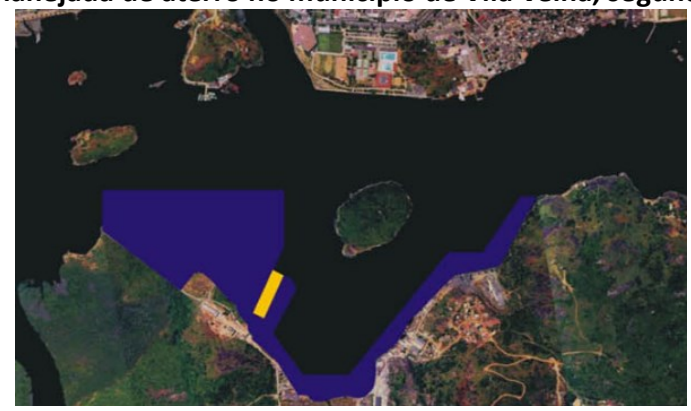

Fonte: CODESA, 2001.

Há uma notável participação de ambientalistas e outros movimentos organizados na reestruturação dos planos em outra área do município de Vila Velha, denominada de Saco do rio Aribiri, área de manguezal, onde fora proposto construção de uma dársena (berço) em 1995, projeto abandonado na revisão de 2001 (CODESA, 2001)

Entretanto, muitas das obras de aterros e impactos na face costeira da ilha de Vitória não encontram respaldo no PDZP vigente. Os aterros realizados nas cercanias do bairro da llha do Príncipe, na capital capixaba, são provas inequívocas da ausência de compasso entre o planejado e o executado. Numa comparação entre figura 5, retirada do PDZP de 2001, e uma imagem de satélite disponível no sítio virtual Google Maps (figura 6), datado de 2017, é perceptível um aumento considerável da área efetivamente aterrada. 


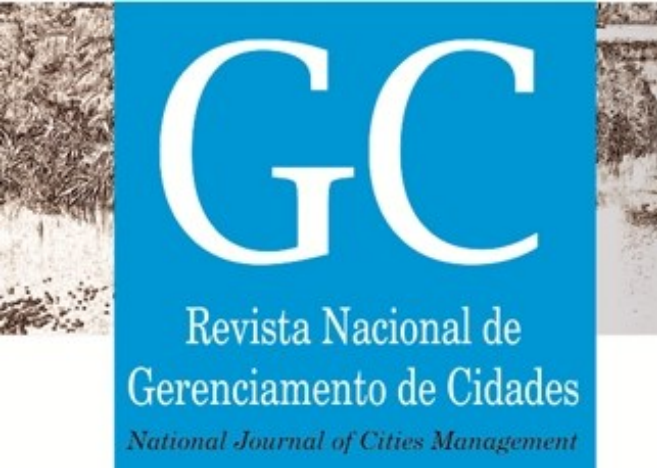

Figura 4: Área planejada de aterro na baía de Vitória, segundo PDZP de 2001 e 1995
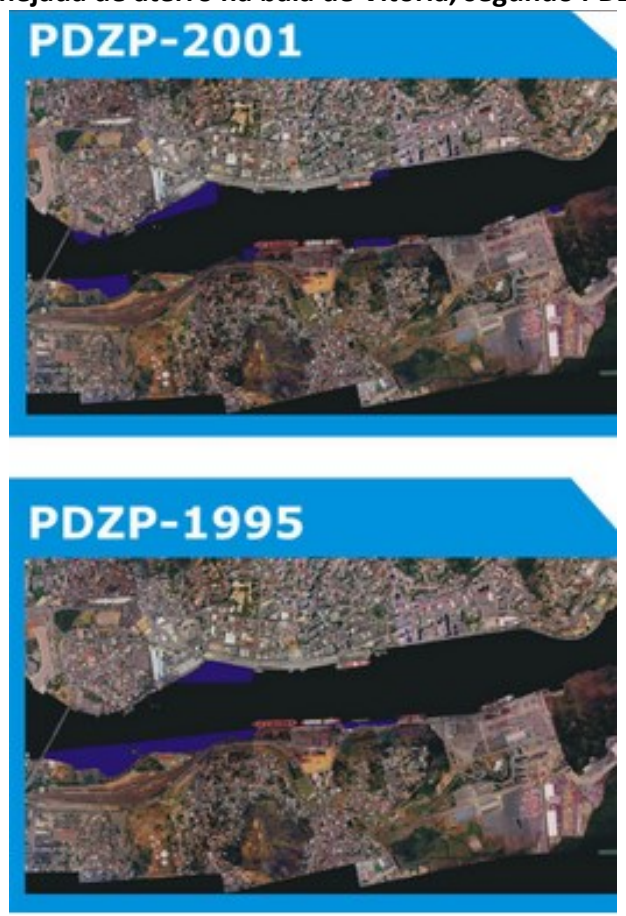

Fonte: CODESA, 2001

Figura 5: Área planejada para aterro no município de Vitória, segundo PDZP de 1995

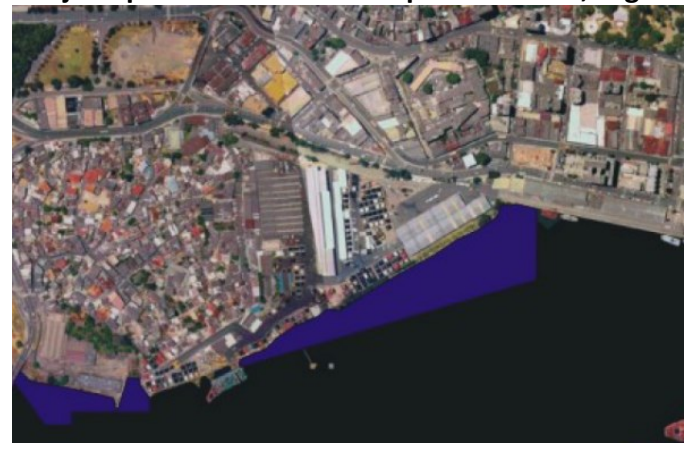

Fonte: CODESA, 2001.

Figura 6: Área efetivamente aterrada no município de Vitória, conforme imagem de satélite

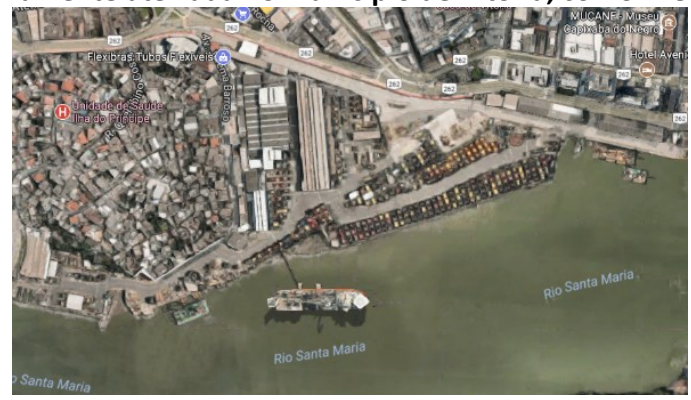

Fonte: GOOGLE MAPS, 2017. 


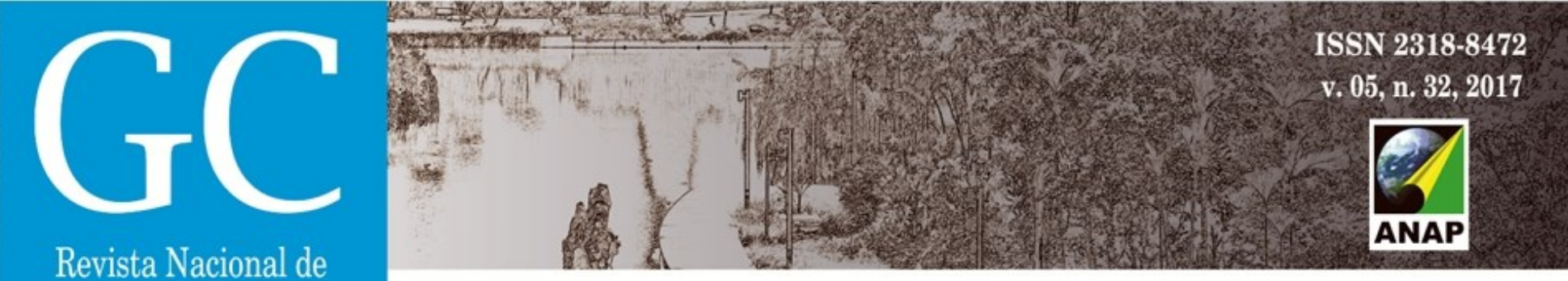

Gerenciamento de Cidades

\section{REFERÊNCIAS}

AGÊNCIA NACIONAL DOS TRANSPORTES AQUAVIÁRIOS (ANTAQ). Disponível em: < http: www.antaq.gov.br>. Acesso em: 30 julho de 2017

CAMPOS, MARTHA M. Vazios operativos da cidade: territórios interurbanos na Grande Vitória (ES). Tese de doutorado. PUC-SP. São Paulo. 2004.

FIM, MINIELLI. Atividade portuária e processos territoriais: Uma abordagem urbanística - Grande Vitória (ES); 31 de março de 2015, 286 f., Tese (Mestrado em Arquitetura e Urbanismo) Programa de Pós-Graduação em Arquitetura e Urbanismo. Universidade Federal do Espírito Santo. Vitória, 2015

HOYLES, B. Cities and ports - concepts and issues. Vegueta, Universidad de las Palmas de Gran Canaria, Facultad de Geografia e Historia, n. 3, 1997 (Inglês)

INSTITUTO ESTADUAL DE MEIO AMBIENTE E RECURSOS HÍDRICOS/IEMA. Parecer técnico n.042/GCA/CAIA. Vitória: IEMA, 2010.

MONIÉ, F.; VASCONCELOS, F. N. Portos, cidades e regiões: novas problemáticas, abordagens renovadas. Confins, n.15, 2012a. Acesso em: 16 de setembro de 2016

.; VIDAL, SORAIA MARIA S. Cidades, portos e cidades portuárias na era da integração produtiva. Rio de Janeiro. 2007a. Disponível em: < http://www.scielo.br/pdf/\%0D/rap/v40n6/03.pdf > Acesso em: 14 de setembro de 2016

ORNELAS, RONALDO S. Relação Porto/Cidade: o caso de Santos; 2008, 141 f., Tese (Doutorado em Geografia) Programa de Pós-Graduação em Geografia Humana. Universidade de São Paulo. São Paulo, 2008

PREFEITURA MUNICIPAL DE VITÓRIA. Agenda Vitória. Eixo Econômico: Portos. 2008, Vitória ES.

CEPEMAR, RIMA Relatório de Impacto de Meio Ambiente do Terminal de Uso Misto de Praia Mole. Vitória, 2008

SOARES, ELIANA A. S.; MOREIRA, F. D. Preservação do patrimônio cultural e reabilitação urbana: o caso da cidade do Rio de Janeiro. da Vinci. Curitiba. v. 4 , n. 1, p. 101-120, 2007

SUPERINTENDÊNCIA DE PORTOS; Relatório de vistoria no. 001/2010-GMA: Avaliação da qualidade de gestão ambiental no Porto de Vitória. 2010, Brasília, DF

VASCONCELOS, F.N. O desenvolvimento da interface cidade-porto em Vitória do período colonial ao início do século XXI: uma cidade portuária? 2011, 463 f. Tese (Doutorado em Ciências Sociais) Programa de Estudos Pós-Graduados em Ciências Sociais, Pontifícia Universidade Católica de São Paulo, São Paulo, 2011 


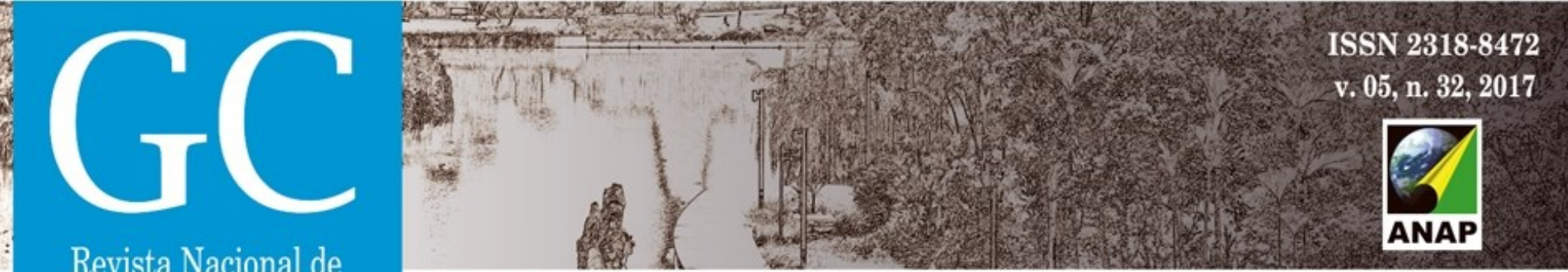

Revista Nacional de

Gerenciamento de Cidades

National Journal of Cities Management

. Os desafios para a legislação ambiental para os Portos: A interface ambiental no Porto de Vitória/ES. 2014. ENANPUR. São Paulo, SP.

VIANA, CASSIO B. ESTEVES. Conflitos de uso na baía de Vitória: Diagnóstico da gestão ambiental portuária e costeira. Monografia do curso de graduação em Oceanografia. Vitória, UFES, 2009 